\title{
ChemComm
}

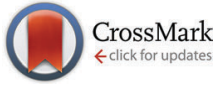

Cite this: Chem. Commun., 2015, 51,5872

Received 17th January 2015

Accepted 6th February 2015

DOI: $10.1039 / \mathrm{c} 5 \mathrm{cc} 00481 \mathrm{k}$

www.rsc.org/chemcomm

\section{Microemulsion flame pyrolysis for hopcalite nanoparticle synthesis: a new concept for catalyst preparation $\dagger$}

\author{
T. Biemelt, ${ }^{a}$ K. Wegner, ${ }^{a}$ J. Teichert ${ }^{a}$ and S. Kaskel ${ }^{\star a b}$
}

\begin{abstract}
A new route to highly active hopcalite catalysts via flame spray pyrolysis of an inverse microemulsion precursor is reported. The nitrate derived nanoparticles are around $15 \mathrm{~nm}$ in diameter and show excellent conversion of $\mathrm{CO}$ under ambient conditions, outperforming commercial reference hopcalite materials produced by co-precipitation.
\end{abstract}

Carbon monoxide is a gas with toxic effects on humans when inhaled at concentrations as low as 100 ppm. ${ }^{1}$ Especially miners, firefighters or soldiers can be confronted with lethal amounts. Hence, it is of special importance to improve protection systems for the decontamination of air. A common method to remove $\mathrm{CO}$ from breathing air is using respirator masks containing active filter media based on either physisorption, chemisorption, or catalytic removal. In the case of catalytic toxic gas conversion by oxidation with ambient $\mathrm{O}_{2}$, many catalytically active components such as oxide supported noble metals ${ }^{2}$ or transition metal oxides $^{3}$ are established. Although catalyst research for the oxidation of $\mathrm{CO}$ was revived with the discovery of Haruta et al., who found gold nanoparticles dispersed on $\alpha-\mathrm{Fe}_{2} \mathrm{O}_{3}$ to be very active even at temperatures as low as $-70{ }^{\circ} \mathrm{C},{ }^{4}$ gold catalysts are prone to poisoning and thus the more robust well-known copper manganese mixed oxide "Hopcalite" is still the commercial catalyst of choice for this reaction.

Hopcalite has been produced by sol-gel processes, ${ }^{6}$ supercritical anti-solvent precipitation, ${ }^{7}$ redox methods, ${ }^{8}$ or most commonly co-precipitation including several partly time consuming preparation steps such as: dissolving the precursors, precipitation, ageing, filtering, washing, drying and subsequent calcination. ${ }^{9}$ This procedure causes contamination with sodium ions resulting from $\mathrm{Na}_{2} \mathrm{CO}_{3}$-containing precipitation solutions,

\footnotetext{
${ }^{a}$ Department of Inorganic Chemistry, Dresden University of Technology, Bergstrasse 66, D-01062 Dresden, Germany. E-mail: stefan.kaskel@chemie.tu-dresden.de; Fax: +49 351 46337287; Tel: +4935146333632

${ }^{b}$ Fraunhofer Institute for Material and Beam Technology, Winterbergstraße 28, D-01277 Dresden, Germany

$\dagger$ Electronic supplementary information (ESI) available: Additional characterization of the inverse microemulsions, nanoparticles and further catalytic measurements. See DOI: $10.1039 / \mathrm{c} 5 \mathrm{cc} 00481 \mathrm{k}$
}

which is known to reduce the catalytic activity to some extent. ${ }^{10}$ Furthermore it is crucial to adjust synthesis parameters such as aging time and calcination temperature thoroughly for receiving the optimal performing hopcalite catalyst., ${ }^{9,11}$

A homogeneous distribution of oxide forming ions on the atomic level is also achieved by the flame spray pyrolysis (FSP) process. It is characterised by the generation of combustible aerosols, containing volatile metal-organic precursors dissolved in a fuel. However, as a major drawback compared to often used metal nitrates, metalorganic precursors usually have high prices or can only be prepared at the lab-scale level. Hence, it is of great interest to combine the benefits of inexpensive metal nitrates and the FSP-process, since the relatively low number of synthesis steps is advantageous. At the same time applying a scalable ${ }^{12}$ and industrially established process contamination with alkali metal ions is avoided.

Considering these requirements for the production of hopcalite by FSP, we used the platform of thermodynamically stable and spontaneously forming inverse microemulsions. They can be understood as a tool box with variable composition but well defined microstructure. Moreover, they contain monodisperse water droplets smaller than $10 \mathrm{~nm}$ in diameter, which should lead to homogeneous doping effects and nanosized particles, simultaneously ensuring sufficiently high nitrate concentrations in a non-polar organic solvent. Metastable emulsions, consisting of large micelles with diameters in the micrometer range, were used for the generation of single and mixed oxides in the emulsion combustion method, but resulted in micronsized, usually hollow and broad size-distributed spheres. ${ }^{13}$

For the preparation of nanostructured stable microemulsions, manganese and copper nitrate (molar ratio $2: 1$ ) were dissolved in deionised water and dispersed in $n$-heptane with the help of the non-ionic surfactant MARLOPHEN NP-5. The turquoise solutions were fed to a nozzle, generating micelle containing $n$-heptane- $\mathrm{O}_{2}$ aerosols, which were instantaneously ignited by an annular surrounding supporting flame. A glass fibre filter was used to separate the black nanoparticles from the exhaust gas stream (more detailed information on hopcalite synthesis is available in the Experimental part of the ESI $\dagger$ ). 
Table 1 Properties of microemulsion derived FSP-hopcalites with respect to the initially applied overall metal concentrations

\begin{tabular}{lllccl}
\hline ME- & $\begin{array}{l}c_{\text {metal }} \\
(\mathrm{M})\end{array}$ & $\begin{array}{l}d_{\text {micelle }}{ }^{a} \\
(\mathrm{~nm})(\mathrm{PDI})\end{array}$ & $\begin{array}{l}S_{\mathrm{BET}}{ }^{b} \\
\left(\mathrm{~m}^{2} \mathrm{~g}^{-1}\right)\end{array}$ & $\begin{array}{c}d_{\mathrm{BET}}{ }^{c} \\
(\mathrm{~nm})\end{array}$ & $\begin{array}{l}\mathrm{Mn} / \mathrm{Cu}^{d} \\
\left(\mathrm{~mol} \mathrm{~mol}^{-1}\right)\end{array}$ \\
\hline 1 & 0.10 & $4.7(0.067)$ & 97 & 11.3 & $1.96 \pm 0.01$ \\
2 & 0.05 & $4.7(0.034)$ & 114 & 9.6 & $1.93 \pm 0.02$
\end{tabular}

${ }^{a}$ Determined by dynamic light scattering. ${ }^{b}$ Calculated from the multipoint BET-method for $0.05<p / p_{0}<0.2 .{ }^{15}{ }^{c} d_{\mathrm{BET}}=6 \cdot\left(S_{\mathrm{BET}} \cdot \rho_{\text {hopcalite }}\right)^{-1}$ assuming mono-disperse spherical primary particles with $\rho_{\text {hopcalite }}=$ $5.485 \mathrm{~g} \mathrm{~cm}^{-3} \cdot{ }^{16}{ }^{d}$ Detected by ICP-OES.

Two inverse microemulsions differing in the total metal content were prepared. Aiming at the formulation of precursors with preferably small micelles, we used the work of Henle et al. as a starting point and applied formulations with $R_{\mathrm{W}}=2\left(R_{\mathrm{W}}=\right.$ $n\left(\mathrm{H}_{2} \mathrm{O}\right) \cdot n$ (surfactant $\left.)^{-1}\right) .{ }^{14}$ These resulted in precursor solutions with very small micelle sizes in the range of $5 \mathrm{~nm}$ for $0.05 \mathrm{M}$ as well as $0.10 \mathrm{M}$ overall metal concentrations. Micelle diameters and properties of the FSP derived particles are summarised in Table 1. Injecting these precursor solutions into the FSP nozzle resulted in two voluminous powders (powder density $\rho_{\text {dump }}=$ $0.15 \mathrm{~g} \mathrm{~cm}^{-3}$ ) denoted by ME-1 and ME-2.

Fig. 1(a) shows sample ME-1, consisting of two types of particles. The main fraction is characterised by very small partly agglomerated chain-like nanoparticles $c a$. 10-15 $\mathrm{nm}$ in diameter. Additionally, larger spheres with diameters ranging from 50-300 nm were observed. These two types of particles result from different formation mechanisms within the spray flame. On the one hand, precursor evaporation and subsequent vapour combustion occurs forming small mono-disperse nanoparticles. On the other hand, precipitation of the precursor at the aerosol droplet surface and subsequent calcination resulting
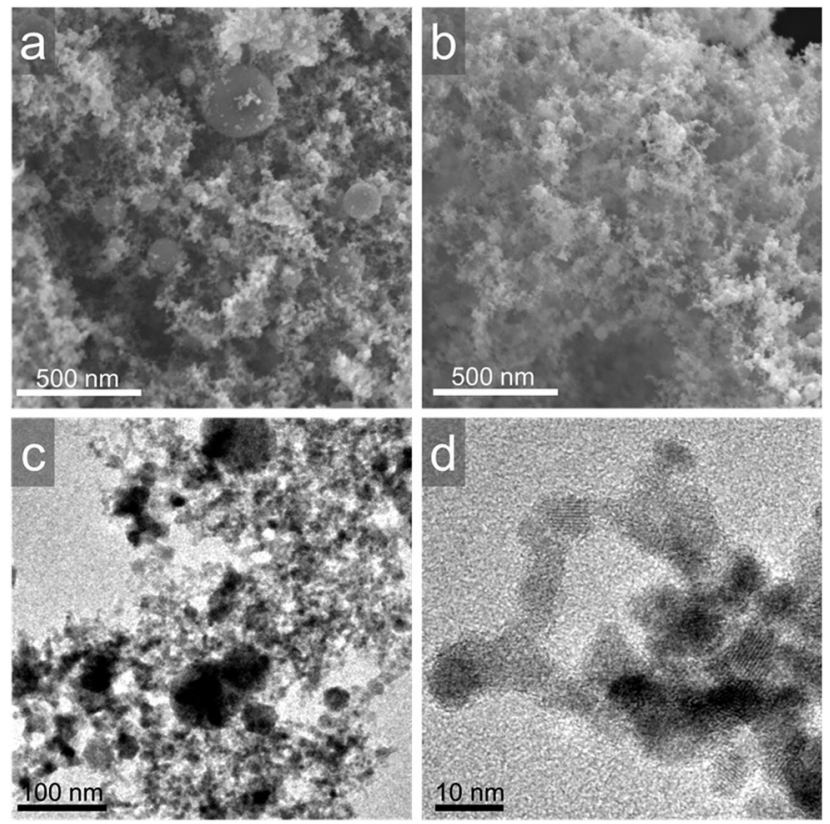

Fig. 1 (a) and (b) SEM micrographs of samples ME-1 and ME-2, respectively. (c) and (d) TEM micrographs of sample ME-2. in poly-disperse, larger and sometimes hollow spheres are possible. ${ }^{17}$ For catalytic applications the first route of the two mentioned formation pathways is preferred, due to the fact that the catalytically available surface area for those particles is higher compared to the precipitation/calcination pathway derived spheres.

In comparison, SEM and TEM micrographs of sample ME-2 in Fig. 1(b)-(d) show higher homogeneity, and a reduced number of larger spheres, visible especially in Fig. 1(b). Nevertheless, besides small either amorphous or crystalline nanoparticles with approximately $10 \mathrm{~nm}$ in diameter, larger spherical particles $c a .50 \mathrm{~nm}$ in diameter were observed by TEM investigations (Fig. 1(c) and (d)). For the amorphous nanoparticles chainlike structures were prominent. Analysing the two differently sized types of particles in ME-1 using electron dispersive X-ray spectroscopy (EDX) revealed differences in $\mathrm{Mn}$ : $\mathrm{Cu}$ ratios of 1.52 for areas with small particles and an elevated ratio of $9.34 \mathrm{~mol} \mathrm{~mol}^{-1}$ for the large spheres. Thus, some segregation in physical binary oxide mixtures occurred during the pyrolysis process. This can be explained by an inhomogeneous temperature profile of the flame including sharp temperature gradients causing different particle formation mechanisms depending on the trod flame-path during pyrolysis. Moreover, $\mathrm{Mn}\left(\mathrm{NO}_{3}\right)_{2}$ and $\mathrm{Cu}\left(\mathrm{NO}_{3}\right)_{2}$ show diverse behaviour during heating. While $\mathrm{Mn}\left(\mathrm{NO}_{3}\right)_{2}$ decomposes at $\sim 140{ }^{\circ} \mathrm{C}$, $\mathrm{Cu}\left(\mathrm{NO}_{3}\right)_{2}$ is more stable against decomposition as reasoned from a melting temperature of $256{ }^{\circ} \mathrm{C}$. These differences may result in a delayed decomposition especially for precursor droplets, not passing the hottest spot of the flame exhibiting temperatures higher than $2000{ }^{\circ} \mathrm{C} .{ }^{18}$

Nitrogen physisorption experiments at $77 \mathrm{~K}$ revealed IUPAC Type II isotherms indicating non-porous nanoparticulate catalysts (Fig. S2, ESI $\dagger$ ). Applying the multipoint BET-method, surface areas of 97 and $114 \mathrm{~m}^{2} \mathrm{~g}^{-1}$ were extracted for ME-1 and ME-2, respectively. The slightly dissimilar specific surface areas result from varying metal ion concentrations within the water phase of the two inverse microemulsions. Both precursors consisted of identical micelle sizes as confirmed by dynamic light scattering measurements (DLS). Dynamic viscosities and refractive indices, resulting from different metal salt concentrations (Table S1, ESI $\dagger$ ), were taken into account for these experiments. Identical micelle diameters imply differences in ion densities within the micelles, inducing a higher degree of agglomeration for nanoparticles derived from ME-1 compared to ME-2 and favouring the precipitation/calcination particle generation pathway caused by reduced energy supply for fast decomposition of the nitrate precursors, as well.

Average particle sizes $d_{\text {BET }}$ were calculated assuming monodisperse spherical particles taking specific surface area and the crystallographic specific mass of $\mathrm{Cu}_{1.5} \mathrm{Mn}_{1.5} \mathrm{O}_{4}\left(\rho=5.485 \mathrm{~g} \mathrm{~cm}^{-3}\right)$ into account. ${ }^{18}$ This calculation yields average particle diameters of 11.3 and $9.6 \mathrm{~nm}$ for ME-1 and ME-2, respectively. The values should be understood as an approximation, since a bimodal size distribution was observed especially for sample ME-1.

FSP-derived hopcalite is composed of two crystalline phases as indicated by powder X-ray diffraction (XRD) in Fig. S1, S6 and S7 (ESI $\dagger$ ). The major component was calculated to be 
$\mathrm{Cu}_{1.5} \mathrm{Mn}_{1.5} \mathrm{O}_{4}$ with 81.2 and $90.4 \mathrm{wt} \%$ for $\mathrm{ME}-1$ and $\mathrm{ME}-2$, respectively. Hausmannite $\left(\mathrm{Mn}_{3} \mathrm{O}_{4}\right)$ as a minor by-product accounts for 18.8 and $9.6 \mathrm{wt} \%$ applying profile fitting and phase quantification by Rietveld refinement for both samples. From these mass fractions the determination of $\mathrm{Mn}: \mathrm{Cu}$ ratios theoretically should yield values of 1.47 and $1.22 \mathrm{~mol} \mathrm{~mol}^{-1}$ for ME-1 and ME-2, respectively. In contrast, ICP-OES revealed bulk

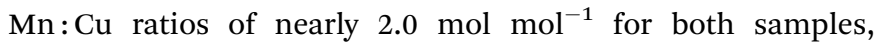
indicating the presence of a manganese-rich amorphous phase which was not detected by XRD.

According to full profile fitting for crystallite size analysis, $\mathrm{Cu}_{1.5} \mathrm{Mn}_{1.5} \mathrm{O}_{4}$ consists of crystallites 13.2 and $17.6 \mathrm{~nm}$ in diameter, and much larger $\mathrm{Mn}_{3} \mathrm{O}_{4}$ crystallites of 261 and $64 \mathrm{~nm}$ were found for samples ME-1 and ME-2, respectively, confirming the bimodal size distribution detected by microscopic investigation. The determined crystallite sizes are larger compared to the particle sizes derived from physisorption measurements. Hence, the particles of the amorphous Mn-rich phase are presumably smaller than $10 \mathrm{~nm}$, thus significantly contributing to the overall specific surface areas of both powders.

Catalytic testing was performed in a fixed bed tubular reactor equipped with two IR-sensors ensuring simultaneous quantification of $\mathrm{CO}$ and $\mathrm{CO}_{2}$. In a typical test setup $100 \mathrm{mg}$ of catalyst were exposed to a mixture of $0.67 \mathrm{vol} \% \mathrm{CO}, 66.00 \mathrm{vol} \%$

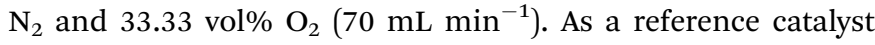
material, commercially available hopcalite Carulite $300\left(S_{\mathrm{BET}}=\right.$ $310 \mathrm{~m}^{2} \mathrm{~g}^{-1}$ ) was chosen.

The catalytic activity was evaluated by plotting the conversion of CO versus catalyst bed temperature. Strongly pronounced differences in $\mathrm{CO}$ oxidation performances among the tested samples were observed (Fig. 2). The densified particles of ME-1 showed CO conversion levels as high as $23 \%$ at ambient temperature and nearly $100 \%$ at $90{ }^{\circ} \mathrm{C}$.

As there was contact with water during the densification step and furthermore with the combustion products of the FSP process possibly adsorbed water molecules, $\mathrm{CO}_{2}$ or hydroxyls on the particle surface were treated with an in situ activation

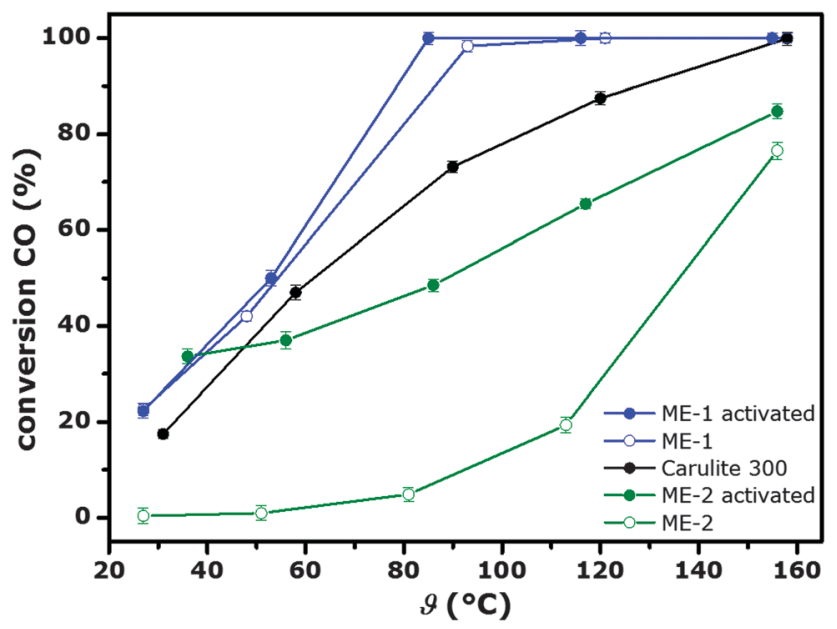

Fig. 2 Conversion of $\mathrm{CO}$ versus catalyst bed temperature for samples ME-1, ME-2 and Carulite 300. step during the catalytic tests. Hence, the catalysts were inertly heated to $300{ }^{\circ} \mathrm{C}$, which is the upper most temperature without inducing significant sintering of the nanoparticles, and afterwards flushed with pure $\mathrm{O}_{2}$ for $1 \mathrm{~h}$.

During the activation process desorbing $\mathrm{CO}$ and $\mathrm{CO}_{2}$ was monitored to collect some information on the nature of molecules possibly covering and poisoning the catalyst surface (Fig. S4, ESI $\dagger$ ). The conversion level did not significantly increase for sample ME-1 as a consequence of activation. This observation is in agreement with the almost complete absence of desorbing $\mathrm{CO}$ and $\mathrm{CO}_{2}$ during activation. In contrast, the as-received sample ME-2 shows low conversion of $\mathrm{CO}$ at ambient temperature and even at higher temperatures there is no significant activity. Activation drastically increased the conversion of CO over ME-2 up to a level of $35 \%$ at room temperature. The desorption profile recorded during activation reveals the generation of $\mathrm{CO}_{2}$ in the case of flushing the system with $\mathrm{O}_{2}$ at $300{ }^{\circ} \mathrm{C}$, indicating the presence of carbonaceous residues at the particle surface presumably poisoning the catalyst in the non-activated state. They either originate from adsorbed $\mathrm{CO}_{2}$, or most-likely from imperfectly oxidised organic compounds such as $n$-heptane or MARLOPHEN NP-5, suggesting that the amount of $\mathrm{NO}_{3}{ }^{-}$, acting as a co-oxidant, is insufficient for complete combustion of C-containing precursor constituents.

In the activated state both FSP derived samples show significantly higher conversion levels of $\mathrm{CO}$ at ambient temperature compared to the commercial reference material. This difference is even more pronounced comparing the $\mathrm{CO}$ reaction rates normalised to the specific surface area at ambient temperature. The conversion of $\mathrm{CO}$ is approximately four times higher for the FSP-derived samples. Performance differences between ME-1 and ME-2 in the activated state probably originate from different amounts of crystalline $\mathrm{Mn}_{3} \mathrm{O}_{4}$, as it is known to be less active compared to pure hopcalite. ${ }^{19}$ Furthermore, slightly larger hopcalite crystallites of ME-2 contribute to a smaller increase of activity in the case of elevated temperatures. One possible reason for the fast reaction rates might originate from the amorphous Mn-rich particles acting as support for $\mathrm{Cu}_{1.5} \mathrm{Mn}_{1.5} \mathrm{O}_{4}$ crystallites and increasing $\mathrm{CO}$ and $\mathrm{O}_{2}$ adsorption and bond cleavage rates. The deactivation profiles of ME-1, ME- 2 and Carulite 300 show the strongest decrease of CO-conversion in the first minutes on stream for Carulite 300, suggesting higher stability for FSPderived particles (Fig. S5, ESI $\dagger$ ). The most stable performance was observed for ME-2 at ambient temperature.

A scalable and versatile synthesis of hopcalite nanoparticles by flame spray pyrolysis was presented for the first time.

The application of inverse microemulsion precursors containing manganese-copper nitrate led to hopcalite nanopowders being composed of mixtures containing nanocrystalline $\mathrm{Cu}_{1.5} \mathrm{Mn}_{1.5} \mathrm{O}_{4}$ particles (approximately $15 \mathrm{~nm}$ in diameter) and larger particles of hausmannite as a minor crystallographic phase with an additional Mn-rich amorphous phase. By decreasing the initial metal ion concentration, the ratio of small nano-crystallites and larger spheres (50-300 $\mathrm{nm})$, resulting from a precipitation/calcination formation mechanism within the flame was increased. The larger particles were found to be mainly composed of manganese oxide. 
Compared to the commercial reference hopcalite material Carulite 300, the FSP derived nanopowders show better CO conversion performances, especially at ambient temperature. Additionally, they are more long term stable. An activation step removes residual carbonaceous deposits at the catalyst surface improving the activity further.

The presented microemulsion flame process generally enables the application of inexpensive water soluble salts for the continuous, scalable and contamination-free production of non-segregated separated complex oxide nanoparticles for various applications. This is achieved by usage of thermodynamically stable and spontaneously forming inverse microemulsions containing very small uniform micelles in the lower nanometer range.

We would like to thank Dr Gudrun Auffermann (MPI for Chemical Physics of Solids, Dresden, Germany) for conducting elemental analyses. Alexander Weiz (Department of Inorganic Chemistry II, Dresden University of Technology, Dresden, Germany) and Dr Martin R. Lohe (Department of Inorganic Chemistry II, Dresden University of Technology, Dresden, Germany) are gratefully acknowledged for their support with preparing STEM and TEM micrographs. We would also like to thank the German Federal Ministry of Education and Research (BMBF) for financial support (03X0126C).

\section{Notes and references}

1 T. Gerhardt, M. Göthert, G. Malorny and H. Wilke, Int. Arch. Arbeitsmed., 1971, 28, 127-140.
2 J. Saavedra, C. Powell, B. Panthi, C. J. Pursell and B. D. Chandler, J. Catal., 2013, 307, 37-47.

3 X. Xie, Y. Li, Z.-Q. Liu, M. Haruta and W. Shen, Nature, 2009, 458, 746-749.

4 M. Haruta, N. Yamada, T. Kobayashi and S. Iijima, J. Catal., 1989, 115, 301-309.

5 A. Bliss, J. Am. Chem. Soc., 1955, 77, 5773-5780.

6 M. Krämer, T. Schmidt, K. Stöwe and W. F. Maier, Appl. Catal., A, 2006, 302, 257-263.

7 Z.-R. Tang, C. D. Jones, J. K. W. Aldridge, T. E. Davies, J. K. Bartley, A. F. Carley, S. H. Taylor, M. Allix, C. Dickinson, M. J. Rosseinsky, J. B. Claridge, Z. Xu, M. J. Crudace and G. J. Hutchings, ChemCatChem, 2009, 1, 247-251.

8 E. C. Njagi, C.-H. Chen, H. Genuino, H. Galindo, H. Huang and S. L. Suib, Appl. Catal., B, 2010, 99, 103-110.

9 G. J. Hutchings, A. A. Mirzaei, R. W. Joyner, M. R. H. Siddiqui and S. H. Taylor, Catal. Lett., 1996, 42, 21-24.

10 A. A. Mirzaei, H. R. Shaterian, R. W. Joyner, M. Stockenhuber, S. H. Taylor and G. H. Hutchings, Catal. Commun., 2003, 4, 17-20.

11 G. J. Hutchings, A. A. Mirzaei, R. W. Joyner, M. R. H. Siddiqui and S. H. Taylor, Appl. Catal., A, 1998, 166, 143-152.

12 R. Mueller, L. Mädler and S. E. Pratsinis, Chem. Eng. Sci., 2003, 58, 1969-1976.

13 T. Tani, N. Watanabe, K. Takatori and S. E. Pratsinis, J. Am. Ceram. Soc., 2003, 86, 898-904.

14 J. Henle, P. Simon, A. Frenzel, S. Scholz and S. Kaskel, Chem. Mater., 2007, 19, 366-373.

15 J. Rouquerol, D. Avnir, C. W. Fairbridge, D. H. Everett, J. H. Haynes, N. Pernicone, J. D. Ramsay, K. S. W. Sing and K. K. Unger, Pure Appl. Chem., 1994, 66, 1739-1785.

16 H. K. Kammler, L. Mädler and S. E. Pratsinis, Chem. Eng. Technol., 2001, 24, 583-596.

17 R. Strobel and S. E. Pratsinis, J. Mater. Chem., 2007, 17, 4743.

18 L. Mädler, H. K. Kammler, R. Mueller and S. E. Pratsinis, J. Aerosol Sci., 2002, 33, 369-389.

19 S. Royer and D. Duprez, ChemCatChem, 2011, 3, 24-65. 